GUIDELINE REVIEW

\title{
Evidence based guidelines for the performance of the sweat test for the investigation of cystic fibrosis in the UK
}

\section{J H Baumer}

Arch Dis Child 2003;88:1126-1127

A well produced evidence based guideline has been developed in response to a national audit that demonstrated wide variations in the performance of sweat tests. Accurate and reliable sweat test results will be particularly important with the advent of neonatal screening. The guideline recommendations include the collection and analysis of sweat samples, and interpretation of results. It emphasises the importance of sweat chloride as the best discriminator.

Correspondence to:

Dr H J Baumer, Derriford Hospital, Plymouth PL6 8DH, UK; harry.baumer@ phnt.swest.nhs.uk

Accepted 11 July 2003
T he quantitative measurement of sweat electrolytes following stimulation by pilocarpine iontophoresis remains vital in supporting the diagnosis of cystic fibrosis despite the emergence of gene mutation analysis. Over 1000 mutations in the cystic fibrosis transmembrane conductance regulator gene on chromosome 7 have been identified. A minority of children with cystic fibrosis have no identifiable gene mutation, and a number of mutations are associated with atypical and very mild clinical manifestations, and with intermediate sweat test results. Accurate analysis of sweat electrolytes is particularly important with the introduction of routine neonatal screening using immunoreactive trypsin with or without DNA testing, which will identify infants with variable phenotype and genotype. This will lead to an increase in the number of sweat tests performed in small infants, and the need for very careful counselling of families.

A recent national audit showed widely variable practice and standards in sweat testing. Concerns included a lack of sweat chloride analysis by some laboratories, variability in reference ranges, lack of quality control, and sporadic reports of adverse events. The Specialist Advisory Group for Paediatric Investigations of the UK National External Quality Assurance Schemes (NEQAS) suggested that an evidence based guideline was needed. Dr Anne Green, Clinical Biochemist, led a multidisciplinary group in developing the guideline, with representation from a number of organisations, and support from the Cystic Fibrosis Trust.

This guideline covers subject suitability, the methods for stimulation and collection of sweat, the performance and quality control of the laboratory test, interpretation of results, and responsibilities for testing and training of health personnel. It does not include detailed indications for undertaking the test.
The guidelines are underpinned by a detailed search and review of the literature, and recommendations are graded A to C, with links to the evidence, which is categorised to four levels (see table 1). The guidelines include recommendations for audit and further research, examples of standard operating procedures for the collection and analysis of sweat, and a suggested patient information leaflet.

Key points from the guideline include:

- It is important to explain the test adequately beforehand, including the reason why it is being undertaken, supported by a written information sheet (grade C).

- Sweat tests can be performed after 2 weeks of age in infants greater than $3 \mathrm{~kg}$ who are normally hydrated and without significant systemic illness (grade C). In term infants, sweat sodium and chloride can be high in the first seven days, especially the first 48 hours (level III evidence).

- Sweat tests should be delayed in subjects who are oedematous or on systemic steroids (grade C).

- Sweat tests can be performed in subjects on flucloxacillin (grade B).

- For safety reasons sweat tests should not be performed in subjects who are on oxygen by an open delivery system. This would not apply to an infant in headbox or on nasal prong oxygen (grade C).

- The stimulation, collection, storage, and analysis of sweat must be performed according to written standard operating procedures consistent with the recommendations in the guideline (grades $\mathrm{B}$ or $\mathrm{C}$ ). All analytical procedures should be supported by internal quality control and external quality assurance. This will ensure both the safety and performance of the test.

- Sweat should be collected for not more than 30 minutes and not less than 20 minutes (grade B).

- Non-standard or hybrid methods for sweat stimulation and collection should not be used (grade B)

- Centres should only analyse sweat if they undertake a minimum number of 50 tests per annum (grade C), with a minimum of 10 collection procedures undertaken per person (grade C).

- Sweat collection must be performed by fully trained personnel, and responsibilities for the provision of testing must be clearly understood (grade C). 
Table 1 Evidence based guideline for the performance of the sweat test for the investigation of cystic fibrosis

\begin{tabular}{|c|c|c|}
\hline $\begin{array}{l}\text { Recommendation } \\
\text { grade }\end{array}$ & $\begin{array}{l}\text { Level of } \\
\text { evidence }\end{array}$ & Description of evidence \\
\hline \multirow[t]{2}{*}{ Grade A } & la & $\begin{array}{l}\text { Evidence obtained from meta-analysis } \\
\text { of randomised controlled trials }\end{array}$ \\
\hline & $\mathrm{lb}$ & $\begin{array}{l}\text { Evidence obtained from at least one } \\
\text { randomised controlled trial }\end{array}$ \\
\hline \multirow[t]{3}{*}{ Grade B } & Ila & $\begin{array}{l}\text { Evidence obtained from at least one } \\
\text { well designed controlled study without } \\
\text { randomisation }\end{array}$ \\
\hline & Ilb & $\begin{array}{l}\text { Evidence for at least one other type of } \\
\text { quasi-experimental descriptive studies }\end{array}$ \\
\hline & III & $\begin{array}{l}\text { Evidence obtained from well designed, } \\
\text { non-experimental descriptive studies } \\
\text { such as comparative studies, correlation } \\
\text { studies, and case studies }\end{array}$ \\
\hline Grade C & IV & $\begin{array}{l}\text { Evidence obtained from expert committee } \\
\text { reports or opinions and/or clinical } \\
\text { experience of respected authorities }\end{array}$ \\
\hline
\end{tabular}

- The sweat secretion rate measured as an average rate over the collection period should not be less than $1 \mathrm{~g} / \mathrm{m}^{2} / \mathrm{min}$ (where $\mathrm{m}^{2}$ is calculated from the area of sweat collection). Collections below this rate should not be analysed. Insufficient sweat collections should not be pooled (grade B). This rate can be achieved in the vast majority of subjects (level IV evidence). UK laboratory data suggest an increase in intermediate chloride results when collections below this rate were analysed (level III evidence). This suggests either that suboptimal sweating (resulting in higher sweat electrolyte concentration) had occurred or that sweat had been lost by evaporation or leakage.

- The sweat test report should include the sweat weight/ volume collected and the minimum acceptable (grade C). The laboratory analysing the sweat must liaise with those collecting the sweat in order to achieve this.

- Sweat chloride is the best discriminator and must always be included in the analysis (grade B).

- A sweat chloride of less than $40 \mathrm{mmol} / \mathrm{l}$ is normal and there is a low probability of cystic fibrosis. A result above $60 \mathrm{mmol} / \mathrm{l}$ supports the diagnosis. An intermediate test result is suggestive but not diagnostic of cystic fibrosis (grade B).

- Sweat conductivity requires further research before it can be relied on for diagnosis. Pending this a sweat chloride must also be measured. A conductivity value below $60 \mathrm{mmol} / \mathrm{l}$ ( $\mathrm{NaCl}$ equivalents) is unlikely to be associated with cystic fibrosis. Values above $90 \mathrm{mmol} / \mathrm{l}$ support a diagnosis of cystic fibrosis (grade B).
- Sweat sodium should not be interpreted without a chloride result. Sweat potassium and osmolality are not recommended (grade $\mathrm{B}$ ).

- There is no routine place for the use of the mineralocorticoid suppression adaptation of the sweat test (grade B).

- Gene mutation analysis can be a useful diagnostic test, particularly in patients with mild or atypical phenotype where sweat chloride concentration may be intermediate (grade B).

\section{COMMENTS}

This is an important subject for a guideline, and addresses an area of concern. With the introduction of routine neonatal screening patients with cystic fibrosis are identified earlier, with indirect evidence of associated long term benefit. Paediatricians will be required to interpret an increasing number of sweat tests in young infants, even with two and three stage screening using DNA analysis.

The Royal College of Paediatrics and Child Health has formally appraised and endorsed the guideline. This involves reviewing the guideline development process using a standard instrument (AGREE, Appraisal of Guideline for Research and Evaluation in Europe) and critically appraising the original studies underpinning each grade $\mathrm{A}$ or $\mathrm{B}$ recommendation. This process indicated that while the methodology employed was generally sound, Medline and Cochrane were the only electronic databases searched for relevant publications. This will have limited the authors' ability to demonstrate the completeness of their supporting evidence. However, this was supported by hand searching and requests to international experts in the field, and some key publications predate the time period covered by electronic databases.

Representation on the guideline development group included clinical biochemists, paediatricians and an adult physician. Informal consensus by the working group was used to address questions where no evidence was available. Although there was no patient or parent representative on the guideline development group, the CF Trust was involved in peer review. A supporting information leaflet for families is included in the guideline, although it is unclear to what extent it has been tested on parents or patients.

There is reasonably strong supporting evidence for some questions despite the absence of randomised controlled trials. Indeed, these would not be appropriate for assessing diagnostic tests. The guideline exposes the lack of any relevant hierarchy of evidence for research supporting the conduct of test procedures.

The guideline may be found at the Association of Clinical Biochemists' website: http://www.acb.org.uk.

The authors did not report any conflict of interest. 